\title{
Effectiveness of Fissure Sealant Retention and Caries Prevention with and without Primer and Bond
}

\author{
Huda Nazar Ana Karina Mascarenhas Sabiha Al-Mutwa Jitendra Ariga \\ Pramod Soparker
}

National School Oral Health Program, Ministry of Health, Kuwait City, Kuwait

\section{Key Words}

Schoolchildren · Sealant · Caries prevention · Sealant retention $\cdot$ Primer and bond

\begin{abstract}
Objective: This study evaluated the effectiveness of sealant retention and caries prevention with and without primer and bond below the fissure sealant among Kuwaiti schoolchildren. Subjects and Methods: This clinical trial used fissure sealant that was applied to four sound first permanent molars on 78 children. All the teeth were cleaned with pumice and rubber cups, isolated with rubber dams, and etched for $20 \mathrm{~s}$. In a split-mouth study design, for the test teeth $(n=156)$, primer and bond (3M Scotchbond Multi-Purpose Plus System primer and bond) were applied below the sealant, and for the control teeth $(n=156)$, only sealant (Delton Plus) was applied. The number of tooth surfaces included was 480 . Due to loss to follow-up, only 60 children were evaluated at 5 years for sealant retention and caries. The evaluation criteria were: completely retained sealant, complete or partial sealant retention, and caries. Results: In teeth sealed with primer and bond, 47 (19.6\%) tooth surfaces had completely retained sealant, $60(9.2 \%)$ teeth had partially retained sealant, while in 51 (21.3\%) caries was prevented and 120 (50\%) tooth surfaces were carious or filled. In teeth sealed without primer and bond, 25\% (60 tooth surfaces) had completely
\end{abstract}

retained sealant, $6 \%$ (14 teeth surfaces) had partially retained sealant, $26 \%$ (54 teeth surfaces) showed caries prevention, and $49.6 \%$ (119 tooth surfaces) were carious or filled. There was no difference between teeth sealed with primer and bond (120 teeth) and teeth sealed without primer and bond (120 teeth) in completely retained sealant ( $p=0.15)$, complete or partial sealant retention $(p=0.6)$, caries prevented $(p=0.37)$, and caries $(p=0.93)$. Conclusion: Caries prevention was not enhanced in teeth sealed with primer and bond sealant compared with those sealed with sealant alone.

Copyright $\odot 2012$ S. Karger AG, Basel

\section{Introduction}

Dental caries is the most prevalent infectious disease worldwide, affecting $60-90 \%$ of schoolchildren in most industrialized countries [1]. According to WHO data, dental caries in 12-year-old children in 2004 was still a concern worldwide with relatively high prevalence and severity [2]. Caries prevalence is also high in Kuwaiti schoolchildren as shown in a study conducted by Vigild et al. [3], in which the mean DMFT for 12-year-olds was 2.0 in 1982 and increased to 2.6 in 1993. Another study by Behbehani and Shah [4] reported that the mean $\mathrm{dmft}$ was 3.9 in 6-year-olds and 3.0 in 8-year-olds, and caries prevalence in permanent teeth was $24 \%$ in children at the

\section{KARGER}

Fax +4161306 1234

E-Mail karger@karger.ch

www.karger.com
(C) 2012 S. Karger AG, Basel

$1011-7571 / 13 / 0221-0012 \$ 38.00 / 0$

Accessible online at:

www.karger.com/mpp
Dr. Huda Nazar

PO Box 5338

22064 Salmiya (Kuwait)

Tel. +96599635155

E-Mail hudanazar@yahoo.com 
age of 7 years and $61 \%$ at the age of 12 years. These results illustrate the severity and high prevalence of caries in $\mathrm{Ku}$ waiti schoolchildren, and the fact that they continue to increase shows the need for oral health programs which were established in Kuwait in the 1980s in collaboration with worldwide universities and institutes such as the University of Kentucky, Lexington, Ky. and Forsyth Institute, Cambridge, Mass., USA. The prevention measures included in these programs were fluoride rinsing or fluoride tablets and fissure sealant applications.

The use of fissure sealant is a common preventive measure included in all the Kuwaiti programs. Despite the institution of the Kuwaiti School Oral Health Program, more recent data show that caries remains a public health issue for Kuwaiti schoolchildren. Survey data collected by the Kuwaiti School Oral Health Program in 2003-2004 showed that the mean dmft was 6 in 6-yearolds and the DMFT was 3 in 12-year-olds. The filled component was 5\% in 6-year-olds and $37 \%$ in 12 -year-olds [5]. This last survey showed the high caries prevalence and severity for Kuwaiti children, and that while some preventive programs might have been in place, these programs did not reach all Kuwaiti schoolchildren.

Reasons for the high prevalence of dental caries in $\mathrm{Ku}-$ waiti schoolchildren are many, including: the frequent sugar intake between meals, unhealthy snacks, high intake of fast food, and the custom of offering sugary foods as an expression of hospitality. Unfortunately, there is no published data on oral hygiene practices in 6- to 9-yearolds in Kuwait. However, in 2007, Al-Shammari et al. [6] determined by self-report questionnaire that the oral hygiene habits of a sample of educated adult Kuwaitis could be improved, as only $62 \%$ of adults brushed their teeth at least twice a day. Further, Akpata et al. [7] found that patients aged 16 and older that had severe caries had a significantly higher frequency of sugar consumption. From these studies one might conclude that Kuwaiti children have approximately the same percentage of sugar consumption and tooth brushing, suggesting that children's oral hygiene habits also need improvement.

Besides oral hygiene and food habits, another reason for the high caries prevalence could be the loss of sealants after application. A 2004 study from Al-Jahra School Oral Health Program found 2-year sealant retention of $80 \%$ for Kuwaiti schoolchildren [8], which was a higher loss than the $5-10 \%$ loss per year reported for permanent molars by Feigal [9]. There is a great need to prevent caries and improve sealant retention in Kuwaiti schoolchildren, and to decrease the high $\mathrm{dmft} / \mathrm{DMFT}$. One way to accomplish this as suggested in some studies [10-13] is by applying bonding materials underneath fissure sealants, thus improving sealant retention and preventing caries. The literature is inconclusive about the use of primer and bond underneath fissure sealant. While some studies support sealant application with primer and bond underneath the sealant to enhance sealant retention [10-13] other studies do not support sealant application with primer and bond [14-17]. Therefore, this study was performed to evaluate which method of sealant application (with or without bond) is effective in improving sealant retention and preventing caries in a high-risk population of Kuwaiti schoolchildren.

\section{Subjects and Methods}

This study was a clinical trial performed in Al-Ahmadi School Oral Health Program in Al-Ahmadi governorate in Kuwait. The study protocol was reviewed by the Ethics Research Committee of the School Oral Health Program, Kuwait-Forsyth and approved before the study commenced. The study population consisted of children from four public schools who had consent forms signed by their parents for the regular prevention and treatment at the school dental clinic during the school year. Both children and parents were blinded as to which teeth were sealed with primer and bond and which were sealed without primer and bond.

The children were examined for inclusion in the study using the following inclusion criteria: healthy children aged between 6 and 9 years, with four sound fully erupted first molars, absence of caries and discoloration in pits and fissures (should be white and not catch with probe). Children with medical problems, such as cardiac diseases and diabetes, were excluded from the study. Between November and December, 2002, 78 children met our inclusion criteria. The examination was done by the same four dentists (H.K., R.A., T.S., and M.H.), who then applied the sealant. The dentists were provided with a written sealant application protocol for both the control teeth (no primer and bond underneath fissure sealant) and for the test teeth (primer and bond underneath fissure sealant). Fissure sealant was applied to occlusal and buccal/ lingual tooth surfaces. A split-mouth study design was used. This resulted in 312 teeth sealed in 78 children; 156 teeth were sealed with primer and bond and 156 teeth were sealed without primer and bond.

In children with odd registration number at their schools, two permanent first molars were sealed using primer and bond below the fissure sealant on the right side while those on the opposing side received sealants without bond. The sides were reversed for the children with even numbers. This split-mouth procedure was followed so that both groups of teeth (test and control) had the same oral environment, amount of food intake, kind of food intake, and oral hygiene practices to control for these factors as they impact caries development. Both the test and control teeth had the same procedures of application except in the test teeth, which had the primer and bond applied under the sealant. The procedure used for fissure sealant application was as follows: (a) teeth were isolated with rubber dam and clamp, then cleaned with pumice and rubber cup, rinsed and dried with an air-water syringe; (b) 


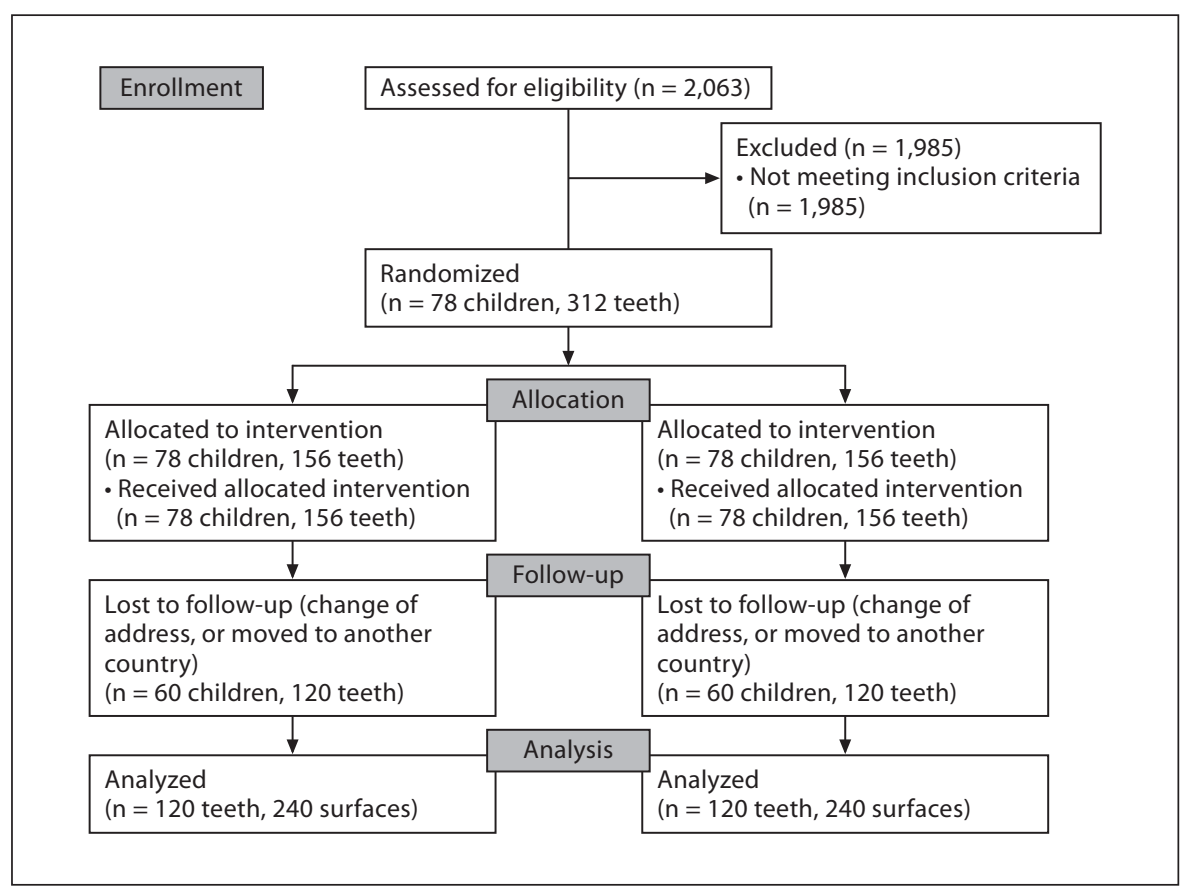

Fig. 1. Flow chart.

Table 2. Matched bivariate analysis for completely retained sealant, complete or partial sealant retention, caries prevented, and caries

\begin{tabular}{llll}
\hline Parameter & OR & $95 \%$ CI & p value \\
\hline Completely retained & 0.59 & $0.33-1.04$ & 0.07 \\
Complete/partial & 0.84 & $0.50-1.40$ & 0.52 \\
Caries prevented & 0.63 & $0.31-1.32$ & 0.22 \\
Caries & 0.62 & $0.40-1.04$ & 0.07 \\
\hline
\end{tabular}

Fissure sealant retention and caries prevention were scored as: Score 1 Sealant completely covering occlusal surface and all buccal pits and palatal fissures

Score 2A Sealant partly covering the tooth and the tooth is sound

Score $2 \mathrm{~B}$ Sealant partly covering the tooth and the tooth is carious

Score 3A Sealant completely lost and the tooth is sound Score 3B Sealant completely lost and the tooth is carious

acid etching gel was applied (3M Scotchbond, 3M-ESPE, St. Paul, Minn., USA) for $15 \mathrm{~s}$ and rinsed for another $15 \mathrm{~s}$, then dried using an air-water syringe; (c) fissure sealant was applied (Delton Plus fissure sealants, Dentsply, York, Pa., USA) using an applicator, then photopolymerized with light cure for $20 \mathrm{~s}$, and (d) the fissure sealant was checked using a mirror and probe for retention.

For test teeth, between steps $b$ and $c$ above, the primer and bond (3M Scotchbond Multi-Purpose Plus System primer and bond) were thinned out using an air syringe, then photopolymerized with light cure for $20 \mathrm{~s}$. All children in the study were recalled each year; from a total of 78 children at baseline, only 60 children participated in this 5-year examination. There was loss to followup due to change of address; some went to other governorates, to private schools, or left the country, so they could not be contacted. All the children with positive consent at their schools received topical fluoride (gel or varnish) as a part of the School Oral Health
Program's protocol. This resulted in the evaluation of 240 teeth, 480 surfaces, 120 teeth sealed with primer and bond below the fissure sealant, and 120 teeth sealed with fissure sealant only. Using a mirror and probe, evaluation for sealant retention and caries (cavitated lesions) was performed by 2 dentists (S.S. and G.A.), who were blinded to the study at Al-Ahmadi School Oral Health Program Dental Center. The criteria shown in table 1 for scoring sealant retention and caries were followed. Caries prevention was recorded when the sealant completely or partially covered the pits and fissures and the tooth was sound. Caries was recorded when the sealant was completely or partially lost and the tooth was carious (cavitated lesion). Also, the number of filled teeth was recorded. The study flow chart reports the enrollment, allocation, follow-up, and analysis for children included in the study (fig. 1).

Data collected were entered into an Excel spreadsheet and then exported to SAS version 9.1. for analyses. Descriptive analysis was 
Table 3. Conditional logistic multivariate regression model predicting completely retained sealant, complete or partial sealant retention, caries prevented, and caries

\begin{tabular}{|c|c|c|c|c|c|c|c|c|}
\hline \multirow[t]{2}{*}{ Parameter } & \multicolumn{2}{|c|}{ Completely retained sealant } & \multicolumn{2}{|c|}{$\begin{array}{l}\text { Complete or partial } \\
\text { sealant retention }\end{array}$} & \multicolumn{2}{|c|}{ Caries prevented } & \multicolumn{2}{|c|}{ Caries } \\
\hline & OR & $95 \% \mathrm{CI}$ & OR & $95 \% \mathrm{CI}$ & OR & $95 \% \mathrm{CI}$ & OR & $95 \% \mathrm{CI}$ \\
\hline Gender (female) & 1.13 & $0.87-1.47$ & 1.05 & $0.80-1.36$ & 1.12 & $0.8-1.6$ & 1.17 & $0.89-1.52$ \\
\hline Age (at application) & 0.90 & $0.78-1.05$ & 0.92 & $0.8-1.07$ & 0.9 & $0.75-1.08$ & 1.01 & $0.85-1.16$ \\
\hline Arch (mandible) & 0.89 & $0.74-1.06$ & 0.85 & $0.71-1.02$ & 0.87 & $0.7-1.07$ & 1.01 & $0.85-1.21$ \\
\hline Bond (yes) & 0.94 & $0.79-1.13$ & 0.98 & $0.8-1.2$ & 1.12 & $0.77-1.17$ & 0.94 & $0.80-1.13$ \\
\hline
\end{tabular}

performed to describe the study sample using frequencies for categorical variables (gender, completely retained sealant, complete or partial sealant retention, caries prevented, caries, tooth status, bond, surface, and arch), and means for continuous variables (age at application, age at evaluation, and years between application and 5-year evaluation). As the study design was a split-mouth design, matched analyses were performed. To control for confounders and account for the split-mouth study design, conditional logistic multivariate regression analysis was performed. Separate analyses were performed for each outcome variable (completely retained sealant, complete or partial sealant retention, caries prevented, and caries), with the main dependent variable being the presence or absence of primer and bond, and controlling for possible confounders (age at application, gender, arch, and surface).

\section{Results}

At 5-year examination, the gender distribution of the 60 children was $52(86.6 \%)$ females and 8 (13.3\%) males, with a mean age of $12.7 \pm 0.64$ years (range 10.8-13.8) while the baseline mean age was $7.7 \pm 0.63$ years (range 5.7-8.8).

At 5 years, the overall results for sealant retention were: $107(22.3 \%)$ surfaces completely retained sealants (score 1), 36 (7.5\%) surfaces partially lost sealants (score 2A and 2B), 218 (45.5\%) surfaces completely lost sealants (score $3 \mathrm{~A}$ and $3 \mathrm{~B}$ ), and 119 (24.8\%) surfaces were filled. In teeth sealed with primer and bond, 47 (19.6\%) tooth surfaces had completely retained sealants, 60 (9.2\%) surfaces had partially retained sealants, in 51 (21.3\%) caries was prevented, and 120 (50\%) surfaces were carious or filled. In teeth sealed without primer and bond 60 (25\%) surfaces completely retained sealant, 14 (6\%) surfaces partially retained sealant, in 54 (26\%) caries was prevented, and 119 (49.6\%) surfaces were carious or filled.

The matched bivariate analysis for completely retained sealant, complete or partial sealant retention, caries pre- vented, and caries is listed in table 2 . The analyses showed that there were no statistically significant differences seen between teeth sealed with primer and bond and teeth sealed without primer and bond in completely retained sealants $(\mathrm{p}=0.07)$, complete or partial sealant retention $(\mathrm{p}=0.52)$, caries prevented $(\mathrm{p}=0.22)$ and caries $(\mathrm{p}=0.07)$.

In the conditional logistic regression analysis (table 3 ) the following outcomes were predicted: completely retained sealant, complete or partial sealant retention, caries prevented, and caries after controlling for confounders (gender, age at application, arch, and tooth surface). There were no differences seen for the entire outcome variables in teeth sealed with primer and bond when compared to teeth sealed without primer and bond. When predicting complete or partial sealant retention, the only statistically significant differences were seen for tooth surface, with sealants on occlusal surfaces less likely to be retained $(\mathrm{p}=$ 0.02 ). Additionally no differences were seen in these outcomes by age, gender, and arch for any of the outcomes.

\section{Discussion}

In this study there were no differences seen in teeth sealed with primer and bond when compared to teeth sealed without primer and bond in enhancing sealant retention and preventing caries. These findings are comparable with studies by Pinar et al. [14] and Boksman et al. [17], which showed even at 2 years no differences in sealant retention rates. However, Venker et al. [15] and Lampa et al. [16] showed that teeth sealed without a bonding agent retained their sealants better than teeth sealed with a bonding agent, but the study duration for both these studies were shorter than for the current study. Venker et al. [15] at 12 months showed that teeth sealed without a bonding agent were 6.4 times more likely to have com- 
pletely retained sealant when compared to teeth sealed with a bonding agent (Prompt-L-Pop, $\mathrm{p}<0.0001$ ) [15], and Lampa et al. [16] at 2 years showed that teeth sealed with NRC/Prime and Bond had only $16 \%$ completely retained sealants, while teeth sealed without the primer and bond had $66 \%$ completely retained sealants.

In contrast to all these studies that show no difference or better results without the use of primer and bond, the studies by Feigal et al. [11, 12] are the only ones that support the use of primer and bond underneath sealants to enhance sealant retention. Feigal et al. [12] found at 5 years that sealant retention was improved when a singlebottle system was used underneath the sealant. Their hazard ratio was $0.53(\mathrm{p}=0.014)$ for occlusal surfaces, whereas in our study the hazard ratio for occlusal surfaces was $1.16(\mathrm{p}=0.11)$ for teeth sealed with primer and bond, indicating a nonprotective effect. Another study by Feigal et al. [11] also showed different results from our study. When teeth were purposely contaminated with saliva before sealant application and Scotchbond was used, 58.3\% of sealants were partially lost; $41.7 \%$ of sealants were partially lost when teeth were not contaminated with saliva and acid etch only was used. However, in our study, in teeth sealed with primer and bond, 9.2\% of sealants were partially lost and in teeth sealed without primer and bond, $5.8 \%$ of sealants were partially lost. Probable reasons for these differences between our findings and the studies that support the use of primer and bond are: difference in application techniques; different kinds of sealant materials used, and different kinds of bonding agents used. Other reasons are sample size, age group, and the duration of the study, all of which could affect the results.

An important finding in this study was that there were no differences between teeth sealed with primer and bond and teeth sealed without primer and bond in caries prevented. The only study that measured caries was the study by Lampa et al. [16]. At 2 years, the authors found that carious teeth were more likely to develop when no bond was used (9\%) when compared to teeth sealed with NRC/Prime and Bond (2\%). No previous studies had evaluated caries prevention at 5 years for teeth sealed with or without primer and bond. In our study, teeth sealed with primer and bond showed $30 \%$ caries prevented and teeth sealed without primer and bond showed $34.3 \%$ caries prevented, indicating that teeth with primer and bond were 0.82 (95\% CI $0.52-1.27$ ) times as likely to protect the teeth from caries (caries prevented) when compared to those sealed without primer and bond. A probable reason might be that fissure sealant alone was not an adequate preventive measure in our high-risk pop- ulation, while another preventive measure - fluoride varnish that is already started in the School Oral Health Program - could be an effective preventive measure. One possible reason for all the widely differing results in these studies is that the type of fissure sealant materials and bonding agents used in these studies differ. This is mostly because these materials, although recommended for use with each other, have not been tested before for compatibility, and therefore these products may not be compatible with each other.

Unfortunately, we did not measure the success rate and loss to follow-up at the dentist level; dentists did not have an equal number of children, since it was difficult to find children meeting our inclusion criteria (four fully erupted sound first molars).

The strengths of this study were: the split-mouth design which was appropriate, because having both control and test teeth in the same child controlled for the factors that may affect sealant retention and caries prevention, such as caries risk, diet, oral hygiene practices [18, 19]; the measurement of the effectiveness of fissure sealant in caries prevention, by measuring caries and filled teeth, which has not previously been done. The main limitation to this study was the small sample size because in a high caries prevalence population of Kuwaiti schoolchildren it was difficult to find children with four fully erupted sound first permanent molars $[5,6]$. Additionally the loss to follow-up further reduced the sample size. Another limitation was that calibration was performed neither at the baseline examination with the four dentists nor at the 5 -year examination with the two examiners. However, the criteria used were simple enough. Based on these results, we recommend that at the current time, in the School Oral Health Program in Kuwait, fissure sealants should be applied without using a primer and bond. Elimination of this step in sealant application will be more cost-effective and less time-consuming because primer and bond are expensive and have not shown effectiveness in enhancing sealant retention or caries prevention among Kuwaiti schoolchildren.

\section{Conclusion}

At the 5-year evaluation, there were no differences in fissure sealant retention and caries prevention in teeth sealed with and without primer and bond among Kuwaiti schoolchildren, for any of the outcomes measured including completely retained sealant, complete or partial sealant retention, caries prevention or caries. 


\section{References}

$>1$ Petersen P: Priorities for research for oral health in the 21 st century - the approach of the WHO Global Oral Health Programme. Community Dent Health 2005;22:71-74.

$>2$ Petersen P, Bourgeois D, Ogawa H, Estupinan-Day S, Ndiaye C: The global burden of oral diseases and risks to oral health. Bull World Health Organ 2005;83:661-669.

-3 Vigild M, Skougaard M, Al-Zaabi F, Al-Yaseen I: Dental caries and dental fluorosis among 4-, 6-, 12- and 15-year-old children in kindergartens and public schools in Kuwait. Community Dent Health 1996;13:47-50.

-4 Behbehani J, Shah N: Oral health in Kuwait before the Gulf War. Med Princ Pract 2002; 11:36-43.

$\checkmark 5$ Al Mutawa S, Shyama M, Al Duwairi Y, Soparker P: Dental caries experience in $\mathrm{Ku}-$ wait school children. Community Dent Health 2006;23:31-36.

6 Al-Shammari K, Al-Ansari J, Al-Khabbaz A, Dashti A, Honkala E: Self-reported oral hygiene habits and oral health problems of Kuwaiti adults. Med Princ Pract 2007;16:413419.
7 Akpata E, Al-Attar A, Sharma P: Factors associated with severe caries among adults in Kuwait. Med Princ Pract 2009;18:93-99.

-8 Francis R, Mascarenhas A, Soparkar P, AlMutawaa S: Retention and effectiveness of fissure sealants in Kuwaiti school children. Community Dent Health 2008;25:211-216.

$\checkmark 9$ Feigal R: Sealant and preventive restorations: a review of effectiveness and clinical changes for improvement. Pediatr Dent 1998;20:8592.

10 Hitt J, Feigal R: Use of a bonding agent to reduce sealant sensitivity to moisture contamination: an in vitro study. Pediatr Dent 1992; 14:41-46.

11 Feigal R, Hitt J, Splieth C: Retaining sealant on salivary contaminated enamel. J Am Dent Assoc 1993;124:88-97.

12 Feigal R, Musherure P, Gillispie B, Levy-Polack M, Quelhas I, Hebling J: Improved sealant retention with bonding agent: a clinical study of two-bottle and single-bottle systems. J Dent Res 2000;79:1850-1856.

13 Burbridge L, Nugent Z, Deery C: A randomized controlled trial of the effectiveness of one-step conditioning agent in sealant placement: 6-month results. Int J Paediatr Dent 2006;16:424-430.
14 Pinar A, Sepet E, Aren G, Bolukbasi N, Ulukapi H, Turan N: Clinical performance of sealants with and without primer and bond. Quintessence Int 2005;36:355-360.

15 Venker D, Kuthy R, Qian F, Kanellis M: Twelve-months sealant retention in a schoolbased program using a self-etching primer/ adhesive. J Public Health Dent 2004;64:191197.

16 Lampa E, Brechter A, van Dijken JW: Effect of nonrinse conditioner on durability of a polyacid-modified resin composite fissure sealant. J Dent Child (Chic) 2004;71:152-157.

17 Boksman L, McConnell R, Carson B, Mc Cutcheon-Jones E: A 2-year clinical evaluation of two pit and fissure sealants placed with and without the use of a bonding agent. Quintessence Int 1993;24:131-134.

18 Klaus G, Juan M: Nutritional role of sugars in oral. Am J Clin Nutr 1995;62:275-283.

19 Benson P, Shah A, Millett D, Dyer F, Parkin N, Vine R: Fluorides, orthodontics and demineralization: a systematic review. J Orthod 2005;32:102-114. 